\title{
La presunción de la donación de órganos en Colombia: reflexiones para el debate
}

The presumption of organ donation in

Colombia: reflections for the debate

A presunção da doação de órgãos na

Colômbia: reflexões para a discussão

Fecha de recepción: 20 de agosto de 2016

Fecha de evaluación: 17 de marzo de 2017

Fecha de aceptación: 2 de mayo de 2017

Disponible en línea: 22 de mayo de 2017

Germán Raúl Chaparro**

\section{Cómo citar:}

Chaparro, G. R. (2017). La presunción de órganos en Colombia: reflexiones para el debate. Revista Latinoamericana de Bioética, 17(2), 92-106.

DOI: http://dx.doi.org/10.18359/rlbi.2178

* Artículo de reflexión.

** Economista; magíster en Economía y estudiante de Doctorado en Historia. Docente e investigador del Grupo de Protección Social, de la Universidad Nacional de Colombia, Bogotá. Correo electrónico: rchaparrog@unal. edu.co. ORCID: http://orcid.org/0000-0002-6443-0021 
La legislación sobre presunción de consentimiento es considerada como una medida efectiva para mejorar las tasas de donación de órganos. En el caso colombiano, este modelo institucional existe desde 1988; sin embargo, en 2016 las leyes de donación han sido reformadas para ratificar el modelo de presunción en una versión fuerte que garantice su implementación, y las nuevas disposiciones evitan que la familia pueda oponerse a la donación de órganos. El presente documento plantea que dicha estrategia no está libre de riesgos y su éxito depende de garantizar la transparencia de la información. Se presenta evidencia empírica y reflexiones teóricas que indican que la relación entre presunción de donación y mayor disponibilidad de órganos no es inequívoca, pues la decisión de donar es muy sensible a la información disponible en el entorno. Se concluye que si la información y los incentivos no son claros los individuos pueden manifestar su negativa a la donación de órganos y, en consecuencia, el sentido de solidaridad en el interior de la comunidad podría ser sacrificado.

Palabras clave: trasplante de órganos, consentimiento informado, presunción de consentimiento, donación post mortem.

\section{Abstract}

The presumed consent legislation is considered as an effective measure to improve organ donation rates. In the Colombian case, this institutional model exists since 1988; however, in 2016 the donation laws were reformed to ratify the model of presumption in a powerful version to ensure its implementation, and the new provisions prevent the family from opposing organ donation. This paper states that such strategy is not risk-free, and that its success depends on ensuring the transparency of the information. We present empirical evidence and theoretical reflections that indicate that the relation between presumed consent legislation and major availability of organs is not unequivocal, since the decision of donation is very sensitive to the available information in the environment. It is concluded that if the information and the incentives are not clear, individuals can express their refusal to the donation of organs and, consequently, the sense of solidarity within the community could be sacrificed.

Keywords: organ transplant, informed consent, presumed consent, post mortem donation.

\section{Resumo}

A legislação sobre presunção de consentimento é considerada como uma medida eficaz para melhorar as taxas de doação de órgãos. No caso da Colômbia, este modelo institucional existe desde 1988; no entanto, em 2016 as leis de doação tem sido reformadas para ratificar o modelo de presunção em uma versão forte para garantir a sua implementação, as novas disposições impedem que a família possa opor-se à doação de órgãos. O presente artigo argumenta que esta estratégia não é isenta de riscos e seu sucesso depende de garantir a transparência das informações. Há evidência empírica e reflexões teóricas que indicam que a relação entre a presunção de doação e o aumento da disponibilidade de órgãos não é inequívoca, pois a decisão de doação de órgão é muito sensível à informação disponível no ambiente; se a informação e os incentivos não são claros os individuos podem expressar a sua recusa à doação de órgãos e, portanto, o sentido de solidariedade no interior da comunidade poderia ser sacrificado.

Palavras-chave: transplante de órgãos, o consentimento informado, presunção de consentimento, doação post mortem. 


\section{Introducción}

La escasez de órganos para trasplante es un problema mundial. El número de personas que esperan por un trasplante crece a un ritmo superior a la disponibilidad de órganos; las listas de espera implican el sufrimiento de personas que requieren un trasplante que les permita restablecer su estado de salud y mejorar su calidad de vida. Los Gobiernos adoptan los modelos legales e institucionales que consideran más adecuados en el propósito de reducir y tratar de eliminar las listas de espera, y al hacerlo intervienen sobre la vida de los seres humanos y generan repercusiones sociales, pues se afectan los valores y principios de la bioética y de la moral que determinan la conducta humana en relación con la alternativa terapéutica del trasplante y las fuentes de obtención de los órganos, en particular, en lo relacionado con las posibilidades de la donación de órganos.

La ciencia ha buscado fuentes de obtención de órganos y tejidos explorando diversos orígenes de abastecimiento. Entre las alternativas se encuentran la organogénesis, creación y utilización de órganos artificiales; los xenotrasplantes, posibilidad de remover células, tejidos y órganos de animales (usualmente cerdos) para trasplantarlos a seres humanos, hecha realidad gracias a los avances de la ingeniería molecular y la genética animal. También se han usado tejidos de fetos humanos procedentes de abortos no inducidos; sin embargo, la utilización de dicho material ha sido cuestionada porque con frecuencia está deteriorado o presenta anomalías genéticas. Otro campo de exploración científica es la clonación, en particular de animales alterados genéticamente para lograr características biológicas compatibles con las de la especie humana. También se ha ensayado la clona- ción directa de órganos y tejidos. No obstante, los resultados en estos campos de investigación hasta el momento no han sido satisfactorios desde el punto de vista técnico y son cuestionados desde una visión ética. Así, dada la tecnología actual, la única fuente de aprovisionamiento es la donación humana, sea en vida o post mortem.

La normativa sobre donación de partes del cuerpo humano puede clasificarse según la forma que adopte el consentimiento de la donación. Un primer modelo se basa en la voluntad expresa del donante, por lo que se denomina consentimiento informado. Un segundo modelo asume que todas las personas son potenciales donantes, a menos que manifiesten su negativa a la donación; este modelo se denomina de presunción de donación. En ambos casos se presentan dos variantes básicas: si se permite o no que la familia se oponga a la donación.

En las últimas décadas, la tendencia mundial ha sido transitar de modelos de consentimiento informado a modelos de presunción de donación $\mathrm{y}$, adicionalmente, adoptar variantes institucionales que impiden, o al menos dificultan, la posible respuesta negativa de los potenciales donantes o sus familiares a la extracción de los órganos. El caso más reciente es Colombia, que en 2016 modificó la normativa sobre donación de componentes anatómicos (Ley 1805). La nueva ley da continuidad al mecanismo de presunción de donación, existente desde 1988 (Ley 73), pero establece que los deudos o familiares no podrán oponerse a dicho procedimiento, salvo que la persona fallecida sea un menor de edad (Congreso de Colombia, 2016).

El presente trabajo pretende reflexionar sobre la pertinencia y posibles riesgos de este tipo de cambios normativos; en ese senti- 
do, el objetivo principal es señalar algunos puntos controversiales o críticos. Se señalan los cambios producidos por las normas legales en los incentivos de los donantes potenciales y sus posibles consecuencias, positivas y negativas, sobre la decisión de donación. Con esta reflexión se espera contribuir al debate público sobre el diseño de la política pública en materia de donación de órganos para trasplante.

La estructura del documento es la siguiente: en la primera parte se presentan las características básicas de los modelos de consentimiento informado y presunción del consentimiento; en la segunda se presentan algunos datos sobre la donación y actividad de trasplantes en Colombia, relevantes para entender la magnitud del problema de escasez de órganos; en la tercera parte se destacan algunos problemas potenciales de los ajustes normativos. Finalmente se presentan las conclusiones.

\section{La norma legal: consentimiento informado o presunto}

El consentimiento de la donación post mortem adopta dos formas legalmente definidas: consentimiento informado o explícito (opt-in o contract-in) o consentimiento presunto (opting out o contracting out). En el caso de la ley de consentimiento informado, la extracción de órganos requiere el consentimiento explícito del donante, lo cual usualmente se realiza a través de una carta o carné de registro como donante. De manera alternativa, en el caso de la legislación de presunción de consentimiento, un individuo que acaba de fallecer es clasificado como donante potencial en ausencia de una oposición explícita, de la persona o de sus deudos, a la donación.

De esta manera, en el consentimiento informado el individuo dispone de mane- ra voluntaria de los derechos de propiedad sobre sus órganos, por cuanto bajo la presunción de donación, tras la muerte, los derechos de propiedad sobre los órganos corporales se convierten en un bien público que pasa a manos del Estado o de la profesión médica, los cuales los asignan a uno de los potenciales receptores dentro de la lista de espera para trasplante.

Ambos modelos de consentimiento imponen costos y beneficios. El tener que manifestar explícitamente la preferencia por donar o no, a través de un registro, impone un costo de transacción para ejercer el derecho de propiedad sobre los órganos corporales. Así, cuando el consentimiento de la donación tiene que ser informado, el donante es quien asume el costo de tomar la decisión de legar sus órganos y de registrarse como donante. Por otra parte, cuando existe la presunción del consentimiento el costo recae sobre las personas que no desean donar, al tener que expresar y formalizar su negativa frente a la donación.

El proceso de registro efectivo de los potenciales donantes parece más complicado bajo un esquema de consentimiento informado, que bajo uno de presunción de donación. Intuitivamente, la política de presunción de donación parte del principio de todos ponen, por lo que parece implicar, per se, que potencialmente habrá más órganos disponibles para trasplante. Una razón que reafirma esta intuición es la expuesta por Reynolds y Barney (1988), quienes señalaron que la política de consentimiento informado recurre al voluntarismo de los donantes potenciales, en tanto que el principio de presunción del consentimiento recurre a la pereza de los individuos a registrarse como no donantes.

Efectivamente, las comparaciones internacionales han mostrado que las leyes de 
presunción del consentimiento están asociadas con incrementos en las tasas de donación de órganos. Por ejemplo, Abadie y Gay (2006, p. 610), en un estudio de 22 países de Europa y Asia entre 1993 y 2002, estimaron que los países con legislación de presunción del consentimiento tuvieron tasas de donación cadavérica entre el $25 \%$ y el $30 \%$ más altas que aquellos países con consentimiento informado. Sin embargo, de ello no se puede inferir que la introducción de la legislación sobre consentimiento informado conduzca per se a un incremento en las tasas de donación, pues hay otros factores determinantes de la tasa de donación, como la disponibilidad de donantes, la organización del sistema de trasplantes y su infraestructura, la inversión en atención en salud y la actitud de la población respecto a la donación y el trasplante (Rithalia et al., 2009).
La figura 1 muestra que la conexión entre la norma legal, las políticas de presunción de donación o consentimiento informado y las tasas de donación, medidas en donantes por millón de personas (pmp), no es inequívoca. Los países con mayor tasa de donación, en efecto, se rigen por normativas de presunción del consentimiento; sin embargo, hay países que teniendo el mismo tipo de normativa presentan tasas de donación comparativamente mucho más bajas. Por otra parte, algunos países, cada vez menos, poseen normativa de consentimiento informado y, no obstante, sus tasas de donación son medianamente altas. La figura 1 pone en evidencia, además, las bajas tasas de donación relativa en los países de Suramérica.

El éxito de un modelo normativo depende de múltiples variables, y en esta reflexión

Figura 1. Donantes fallecidos por millón de personas (pmp) y tipo de consentimiento (2014-2015)

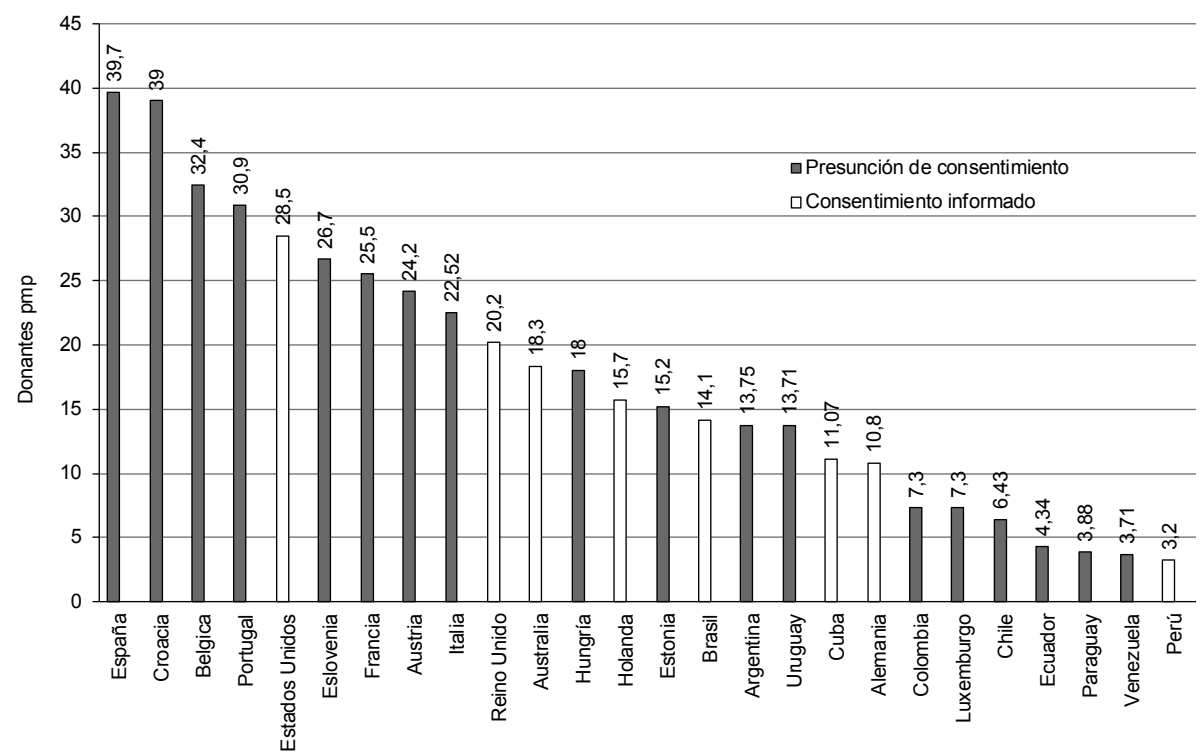


que se proponen dos esenciales que se destacan: el costo relativo de expresar la voluntad respecto a la disposición a donar los órganos y el papel de la familia.

El costo relativo de manifestar la voluntad, sea esta para donar en un sistema de consentimiento informado o para manifestar la negativa a la donación en un sistema de presunción del consentimiento, influye en el resultado del modelo normativo. Por ejemplo, desde una política de presunción de donación, si el costo implicado en el proceso de manifestar la negativa a donar es muy bajo y los donantes potenciales valoran conservar el cuerpo intacto tras la muerte -lo cual puede ocurrir, entre otras razones, por motivos religiosos-, el resultado puede ser que la mayoría de donantes potenciales manifiesten su negativa ante la posibilidad de donación y en consecuencia la cantidad de órganos disponibles para trasplante sea escasa (Kaserman y Barnett, 1991). De manera análoga, desde un modelo de consentimiento informado, si el balance de costos y beneficios de registrarse como donante es lo suficientemente bajo, o incluso si se obtienen beneficios por dicho registro, el resultado puede ser que la mayoría de la población manifieste su voluntad en favor de la donación de órganos.

El papel de la familia también es fundamental en el resultado final de un modelo de donación. En la mayoría de los países del mundo el contenido y la puesta en práctica de las leyes de donación, independientemente de que la norma estipule que el consentimiento de la donación es informado o presunto, prevén que la última palabra sobre la donación de órganos la tengan los parientes directos o los herederos legales de la persona que acaba de fallecer. En España, por ejemplo, como en la mayoría de los países con presunción del consentimiento, incluso cuando la remoción de órganos pueda llevarse a cabo por ley sin el consentimiento de la familia, los coordinadores a cargo del proceso de donación no autorizan la extracción de órganos sin la aprobación explicita de la familia (Abadie y Gay, 2006, p. 602).

El consentimiento familiar es complejo. Los miembros sobrevivientes de la familia, en un momento de dolor intenso, se ven enfrentados a tomar una decisión que implica balancear los beneficios y los costos de permitir la ablación de los órganos de la persona que acaba de fallecer. Los beneficios para la familia del donante son básicamente dos: saber que se puede salvar la vida de otra persona y cumplir la voluntad de su ser querido respecto a la donación (Reynolds y Barney, 1988, p. 575). En este punto adquiere importancia el carné de donación, pues en la práctica es el instrumento que revela las preferencias de donación del individuo, y cumple así la función de proporcionar una señal clara a los miembros de su familia y a las agencias de procuración de órganos (Byrne y Thompson, 2001, p. 73).

Sin embargo, la familia no siempre respeta la intención de la persona que acaba de fallecer. Los costos asociados a ratificar, o no, el consentimiento de la donación implican enfrentarse a los prejuicios sociales y culturales en torno a la muerte y la donación; por ejemplo, las emociones ante la desmembración del cuerpo y las creencias religiosas. Además, la decisión familiar es extremadamente sensible a la percepción que se tiene de variables como la calidad de la atención médica que acaba de recibir un ser cercano y la forma como se lleva a cabo el proceso de solicitud de la donación (Rodrigue, Cornell y Howard, 2006). 
El número de familias que se opone a la donación, es decir, que no dan el consentimiento o reversan la decisión del donante, tiende a ser más grande en países con consentimiento informado, que en los países con presunción de donación. En Estados Unidos y en el Reino Unido, países con consentimiento informado, aproximadamente la mitad de las familias a las que se les solicita la donación la rechazan. En países donde existe presunción de donación el rechazo familiar es comparativamente menor; por ejemplo, en España es cercano al $20 \%$ y en Francia al 30\% (Abadie y Gay, 2006, p. 600).

Abadie y Gay (2006) proporcionan una explicación teórica de cómo cuando las familias toman la decisión final sobre la donación de órganos, las leyes de presunción de consentimiento pueden inducir a tasas de consentimiento familiar más altas. En países con presunción de donación, los individuos con aversión fuerte a la donación de sus órganos no se registran como no donantes por los costos implicados en manifestar su negativa, y al no haber oficializado su voluntad de no donar, las familias infieren que la persona que acaba de fallecer tenía una preferencia favorable a la donación; por tal razón, no se oponen a la extracción de los órganos. Por otra parte, bajo la ley de consentimiento informado es posible que individuos con preferencias fuertes hacia la donación no manifiesten su intención, por el costo de transacción implicado en el registro como donante. Como resultado de esto, las familias infieren que los individuos no registrados tienen en promedio una preferencia débil hacia la donación, lo que induce el rechazo de la familia a donar.

Tasas bajas de donación de órganos y tasas altas de negativa familiar al consentimien- to pueden indicar la presencia de una fisura cultural, una contradicción entre las palabras y los hechos; es decir, una inconsistencia entre disposición alta a donar y las tasas bajas de registro como donantes. Adicionalmente, revela la presencia de asimetrías de información entre el donante y su familia respecto a la voluntad de donación, originadas en la posible aversión a comunicar a la familia los aspectos relacionados con la muerte.

En Estados Unidos, una encuesta de Gallup Organization (1993) parece confirmar la idea de una fisura cultural, pues a pesar de que el $85 \%$ de los encuestados manifestó una opinión favorable hacia la donación, y que el $69 \%$ afirmó estar dispuestos a donar sus órganos después de muertos, el $42 \%$ había tomado la decisión de donar sus órganos. En definitiva, solo el $28 \%$ había concedido el permiso formal para la extracción de órganos a través de su licencia de conducción o un carné de donación. Además solo el $25 \%$ de los encuestados había tomado una decisión acerca de la donación de los miembros de la familia y cerca de una tercera parte (36\%) admitió algún nivel de incomodidad al tratar aspectos relacionados con su propia muerte (Gallup Organization, 1993).

Barcellos et al. (2005), en un estudio llevado a cabo en Brasil, encontraron que a pesar de que el $52 \%$ de los entrevistados estaba dispuesto a donar, solo el 58\% habían expresado tal deseo a sus familiares. La mayoría $(80,1 \%)$ estaría dispuesta a autorizar la donación de los órganos de un familiar siempre y cuando este hubiese manifestado su intención. Cuando este aspecto no se ha discutido en la familia, únicamente una tercera parte de las personas autorizarían la donación. De acuerdo con el estudio, cuando las personas no tienen suficiente información acerca de 
los deseos de los miembros de la familia con respecto a la donación, la tasa de consentimiento familiar a la donación de órganos es más baja.

\section{La evolución de la donación y trasplante de órganos en Colombia}

En Colombia la reducción en el número de donaciones voluntarias presentado en 2013, año cuando se presentaron 329 donaciones, frente a las 474 de 201, condujo a que en 2014 se presentara una propuesta de reforma de la ley de donación de órganos, proceso que finalizó con la sanción de la Ley 1805 de 2016. A continuación se señalan algunas cifras importantes de la actividad de donación y realización de trasplantes.

\section{La actividad del trasplante en Colombia}

La actividad de trasplantes mostraba una tendencia creciente desde el momento cuando se dispusieron estadísticas comparables, a finales de los años noventa, hasta 2010; en los años siguientes, según los datos del Instituto Nacional de Salud (INS), el número de trasplantes muestra una tendencia decreciente, aunque parece repuntar en el último año disponible, 2014 (figura 2).

Esta reducción en el número de trasplantes realizados es consecuencia de la disminución de órganos disponibles, tendencia que es determinada por la evolución del trasplante renal (figura 3), por ser este el más común. En este caso, la reducción en la disponibilidad de riñones de origen cadavérico ha presionado al alza el incremento de la donación en vida.

Figura 2. Actividad de trasplantes en Colombia (1999-2014)

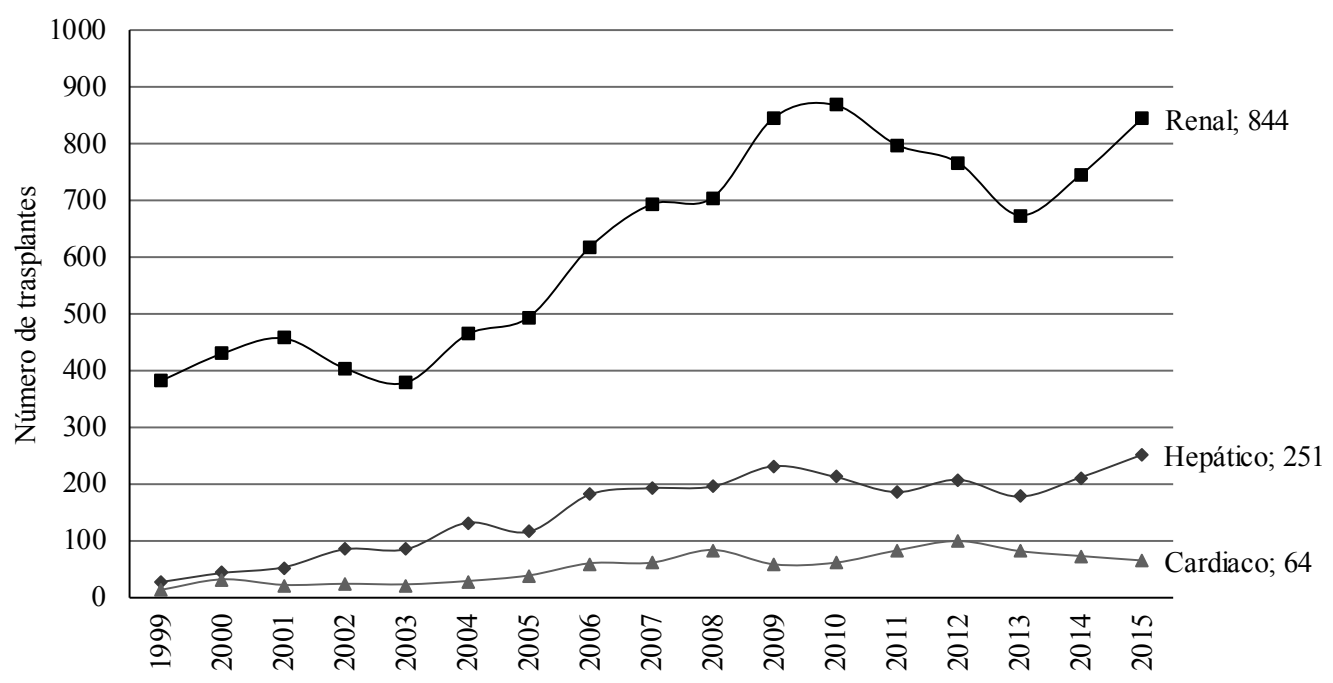


Figura 3. Trasplantes renales según tipo de donante, Colombia (1998, 2002, 2005-2014)

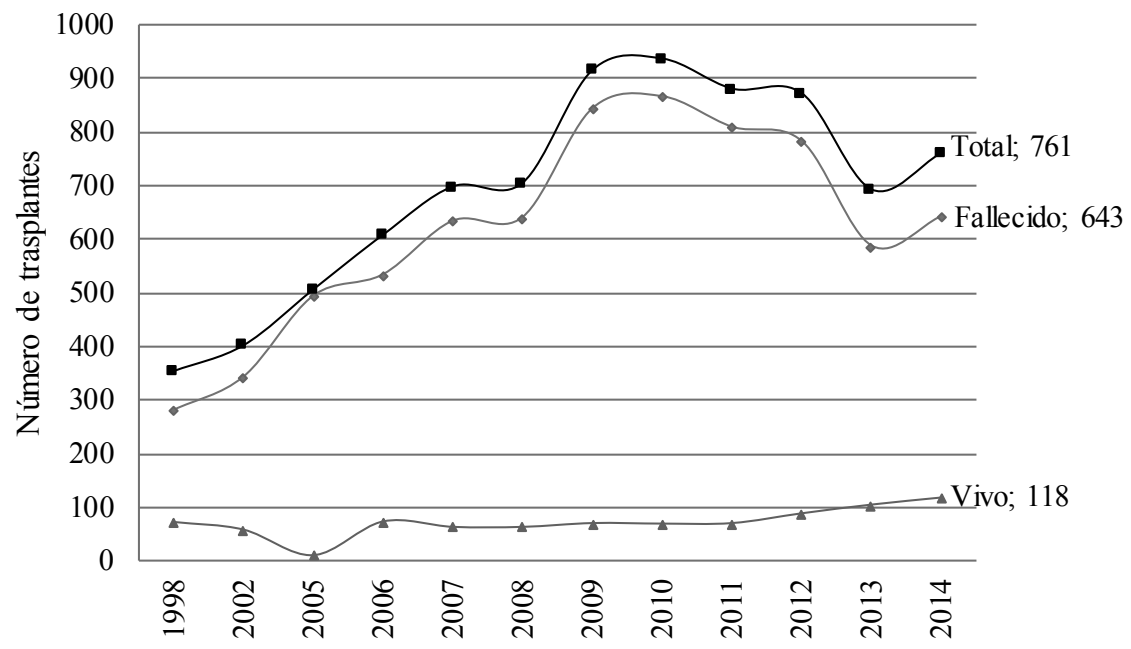

Fuente: elaboración propia, a partir de datos de INS reportados al Irodat.

En el caso colombiano, como en el de muchos otros países, es factible que existan problemas de información. Por ejemplo, en lo que se refiere la tasa de recuperación de riñones de origen cadavérico, Colombia estaría registrando niveles muy superiores al promedio mundial (tabla 1), lo que debería ser verificado. Según el Irodat (2016), en Colombia la tasa de trasplante renal en 2014 fue de 15,97 pmp, bastante baja si se le compara con la tasa registrada el mismo año por países como España (57,26 pmp), Estados Unidos (53,8 pmp), Argentina (31,01 pmp), Brasil (30,1 pmp) o Uruguay (41,64 pmp). En el caso de Estados Unidos, en 2014 la cantidad de personas donantes de riñón fue de 7763; con estos órganos se realizaron 11.570 trasplantes renales. Es decir, que por cada donante cadavérico se logró recuperar, en promedio, 1,49 riñones. En Colombia, en el mismo año, según las es- tadísticas, se lograron recuperar 1,86 riñones por cada donante fallecido. ${ }^{1}$

1 Una dificultad en el trasplante de órganos de origen cadavérico es la restricción temporal, pues una vez muere el donante potencial hay que producir una serie de hechos de manera inmediata: un médico debe decretar la muerte del paciente, obtener el consentimiento de los familiares, realizar la ablación de los órganos y transferirlos de inmediato a una cirugía de trasplante. Los órganos retirados permanecen en condiciones óptimas para el trasplante entre 48 y 72 horas en el caso de los riñones y entre 24 y 48 para los hígados. La restricción de tiempo dificulta encontrar a los potenciales receptores con las características de histocompatibilidad apropiadas, por lo cual no se pueden aprovechar todos los órganos disponibles. Otras posibles causas pueden ser la falla en los métodos de preservación de los órganos y de su transporte, o la ineficiencia del sistema de distribución de estos. Estos aspectos para el caso de Estados Unidos se deben minimizar, tanto por la innovación tecnológica en el cuidado de los órganos como por el hecho de que la asignación de órganos la realiza de manera instantánea un programa de computadora de acuerdo con un conjunto de criterios objetivos (Chaparro, 2016, p. 117). 
Tabla 1. Donación y trasplantes renales, Colombia (2005-2014)

\begin{tabular}{ccccccccc}
\hline & \multicolumn{3}{c}{ Donación } & \multicolumn{3}{c}{ Trasplantes } & Tasa de recuperación \\
\cline { 2 - 6 } Año & $\begin{array}{c}\text { Donantes } \\
\text { post } \\
\text { mortem }\end{array}$ & $\begin{array}{c}\text { Donantes } \\
\text { vivos }\end{array}$ & $\begin{array}{c}\text { Con riñón } \\
\text { de origen } \\
\text { cadavérico }\end{array}$ & $\begin{array}{c}\text { Con riñón } \\
\text { de donante } \\
\text { vivo }\end{array}$ & Total & $\begin{array}{c}\text { de riñones de origen } \\
\text { cadavérico }\end{array}$ \\
\hline 2005 & 276 & 6,9 & 12 & 0,3 & 494 & 12 & 506 & 1,79 \\
\hline 2006 & 396 & 9,9 & 82 & 2,1 & 534 & 74 & 608 & 1,35 \\
\hline 2007 & 449 & 10,7 & 70 & 1,7 & 634 & 64 & 698 & 1,41 \\
\hline 2008 & 428 & 9,6 & 71 & 1,5 & 641 & 64 & 705 & 1,52 \\
\hline 2009 & 554 & 12,3 & 79 & 1,7 & 844 & 71 & 915 & 1,52 \\
\hline 2010 & 569 & 12,5 & 72 & 1,6 & 866 & 70 & 936 & 1,61 \\
\hline 2011 & 501 & 11 & 78 & 1,7 & 809 & 71 & 880 & 1,65 \\
\hline 2012 & 474 & 10,2 & 94 & 2 & 782 & 89 & 871 & 1,78 \\
\hline 2013 & 329 & 7 & 118 & 2,5 & 587 & 105 & 692 & 1,86 \\
\hline 2014 & 346 & 7,3 & 139 & 2,9 & 643 & 118 & 761 & \\
\hline
\end{tabular}

Fuente: elaboración propia, a partir de datos del INS reportados al Irodat (2016).

En la práctica, la donación en vida se produce entre personas allegadas, bajo la forma de altruismo familiar, y no es viable pensar que esa práctica se extienda de manera general por fuera de esas redes de solidaridad primaria, al menos sin que exista la sospecha de pagos por "debajo de la mesa". Por ello, esta fuente de obtención de órganos se considera complementario a la donación post mortem.

En este punto, también conviene aclarar que los modelos de consentimiento, sea informado o presunto, son las únicas alternativas posibles en un escenario donde la normatividad legal prohíbe recibir compensaciones económicas a cambio de la donación de órganos. Esto significa que al margen de la ley existe un tercer modelo, el cual consiste en utilizar incentivos financieros como mecanismo para garantizar el aprovisiona- miento de órganos. En la práctica, este modelo se materializa en un mercado negro de órganos, una actividad ilegal que al no estar regulada produce resultados cuestionables desde el punto de vista ético, médico y social, y cuya actividad se incrementa en contextos de escasez de órganos. ${ }^{2}$

\section{El ajuste normativo en Colombia}

La reducción de las tasas de donación junto a un porcentaje de negativa familiar del $36,9 \%$, el cual registró un aumento del 11,8\% entre enero y septiembre de 2013 con respecto del mismo periodo de 2012, condujeron a que el

2 Algunas propuestas teóricas abogan por eliminar la prohibición, es decir, proceder a la legalización de un mercado de órganos. Los trabajos clásicos en este sentido son los de Gary S. Becker (Becker y Elias, 2007). Para un análisis simplificado de esta propuesta véase el trabajo de Chaparro (2016). 
Congreso de la República de Colombia se propusiera la modificación de las normas vigentes, Ley 73 de 1988 y la Ley 919 de 2004, sobre donación de órganos y material anatómico (Congreso de Colombia, 2014).

Un elemento que vale la pena destacar es el hecho de que las discusiones que condujeron al ajuste de las normas legales están basadas en la experiencia de la donación de 2012 y 2013. Sin embargo, la tendencia en la tasa de donación y de actividad de trasplantes de los años anteriores era creciente y en 2014 y 2015 volvió a repuntar. Aunque la tasa de donación de 7,3 donantes pmp, registrada en 2014, es modesta en términos relativos, el buen diseño de la política pública, en particular en temas tan sensibles como el trasplante de órganos, debería tener en cuenta toda la información disponible.

El resultado del trámite parlamentario fue la sanción de la Ley 1805 de 2016 (Congreso de Colombia, 2016). Con la reforma se ratifica la presunción de donación, vigente desde la Ley 73 de 1988, y se incorpora un elemento sustantivo orientado a garantizar que se cumpla tal presunción. Se trata de una regla según la cual "la voluntad de donación expresada en vida por una persona solo puede ser revocada por ella misma y no podrá ser sustituida por sus deudos y/o familiares" (artículo $2^{\circ}$, parágrafo $1^{\circ}$ ).

Para garantizar el derecho a manifestar la oposición a la presunción legal de donación de órganos y tejidos, se establece que dicha voluntad debe expresarse

[...] mediante un documento escrito que deberá autenticarse ante Notario Público y radicarse ante el Instituto Nacional de Salud (INS), También podrá expresarse la negativa a la donación al momento de la afi- liación a la Empresa Promotora de Salud (EPS), la cual estará obligada a informar al Instituto Nacional de Salud (INS). (Ley 1805 de 2016, artículo 4)

La ley en cuestión también incorpora un elemento nuevo de prioridad o regla de reciprocidad:

En aquellos casos en los cuales dos (2) personas en lista de espera de trasplante de órganos o tejidos sean médicamente compatibles y tengan el mismo nivel de gravedad, el órgano o tejido será trasplantado a la persona que hizo expresa su voluntad de ser donante de órganos y tejidos y se encuentre identificada como tal. (Ley 1805 de 2016, artículo 14)

\section{Algunos retos del modelo de presunción de donación colombiano a la luz de la experiencia chilena}

Colombia modificó su legislación para transitar hacia una versión fuerte de la presunción de donación; sin embargo, esta estrategia no está libre de riesgos. A continuación se señalan algunas enseñanzas de la experiencia chilena, y en particular se enfatiza un posible conflicto de incentivos que cualquier modelo de donación de órganos debe resolver.

En octubre de 2003 Chile modificó su normativa de donación de órganos incorporando reglas de "consentimiento presunto" y un principio de "reciprocidad". De acuerdo con este principio, la voluntad de donar se convierte en un requisito para ser receptor de un órgano en caso de necesitarlo. La reforma fue producto de la disminución en las tasas de donación de órganos entre 2000 y 2002, que condujo a que el número de los donantes se 
redujera de 147 a 117. Así, la Ley de Donación de Órganos (Ley 20,413), que entró en vigencia en enero de 2010, estableció la presunción de donación y creó un comité de coordinación de trasplantes y un listado de no donantes, el cual se realizó ante el Registro Civil, al momento de obtención o renovación del carné de identidad o de la licencia de conducir.

Una consecuencia no esperada de la reforma chilena fue una caída drástica en la donación de órganos, que pasaron de 111 en 2009 a 92 en 2010, la donación más baja desde 1995 (Zúñiga, 2015, p. 1332). La tasa media de donación entre 2000 y el 2009 había sido de 8,31 pmp; en tanto que entre 2010 y 2011, luego de establecerse la presunción de donación, se redujo a 5,95 donantes pmp; esto es una reducción del $29 \%$. El rechazo familiar que había fluctuado entre el $32 \%$ y el $41 \%$ en el periodo $2000-2009$ se incrementó a un máximo histórico de 50,4\% en 2011 (Domínguez y Rojas, 2013). Finalmente, en diciembre de 2011, el 37\% de las personas que renovaron el documento de identificación o la licencia de conducción se registró como no donante. En conclusión, en Chile la norma de presunción de la donación no incrementó la donación de órganos.

En 2011, un estudio de la Universidad Diego Portales (2011) mostró que cerca del $75 \%$ de los chilenos desconocían la nueva ley y el $12 \%$ se manifestó en desacuerdo con la donación de órganos para trasplante. Dentro de las razones se encuentra que el 16\% consideraba que la donación y el trasplante de órganos estaba asociado a algún tipo de mercado o negocio; el $12 \%$ pensaba que los órganos solo se asignaban a la "gente acomodada" y el 12,4\% manifestó su temor a que los médicos "los dejen morir" o a que "le robaran los órganos" al paciente. Estos datos indican la importancia, en el diseño de los programas de procuración de órganos, de garantizar la suficiencia y la transparencia de la información y de la comunicación, porque la ausencia de estas o su distorsión afectan de manera sensible la decisión de los donantes potenciales.

En este sentido, Cosse y Weisenberger (2000) han mostrado cómo las campañas publicitarias que buscan educar al público sobre la necesidad de firmar un registro de donación, y de informar a los miembros de la familia sobre la decisión, tienen efectos positivos en la cantidad de donantes. Los medios de comunicación son una fuente importante de información, pero buena parte de esta resulta perturbadora, pues si bien se difunde información tanto positiva como negativa asociada a la donación de órganos, las imágenes positivas son en general menos memorables que las noticias negativas. La información sensacionalista y negativa refuerza mitos como la declaración prematura de la muerte de los donantes, la transferencia de los rasgos de la personalidad del donante al receptor, la existencia de un mercado negro, la corrupción en la comunidad médica y la manipulación indebida en la asignación de órganos (Morgan et al., 2005).

En particular, Richard Titmuss (1972) analizó los elementos básicos de la tensión entre altruismo e incentivos financieros en el caso del aprovisionamiento de sangre a principios de los años setenta y algunas de sus reflexiones son pertinentes en el caso de la obtención de órganos para trasplante. Titmuss comparó los medios voluntarios y comerciales para obtener sangre para propósitos médicos. Se trata de un estudio comparativo entre los sistemas de aprovisionamiento de sangre entre el Reino Unido, donde la donación se consideraba expresión del altruismo, y el de Estados Unidos, donde 
se habían permitido la comercialización de la sangre. El estudio demostró que el sistema británico, voluntario y socializado, proporcionaba sangre de mayor calidad, medida como la probabilidad de que los receptores se contagien de hepatitis y otras enfermedades de menor incidencia, desperdicia menos sangre, y se presenta menor escasez, que en el sistema, comercial e individualista, aspecto prevaleciente en Estados Unidos.

Titmuss derivó de su argumentación dos corolarios: el primero es la vulnerabilidad del sistema voluntario frente a incentivos mercantiles; así, por ejemplo, si en un país donde se encuentra establecido un sistema voluntario de donación de sangre, e independientemente de la eficacia de este sistema, irrumpen las fuerzas del mercado, esto es, se permite un pago a cambio de la donación, la consecuencia es la desestabilización del sistema voluntario. Segundo, la desestabilización del sistema altruista implica la destrucción irreversible de los valores imperantes en una sociedad, es decir, existe un efecto desplazamiento o salida de los altruistas cuando advierten la presencia de incentivos mercantiles. Titmuss plantea que altruismo y mercado son dos sistemas excluyentes.

La hipótesis del efecto desplazamiento propuesta ha sido contrastada por Frey y Oberholzer (1997), quienes argumentan, en general, que la introducción de pagos monetarios reduce la motivación intrínseca a comportarse de manera altruista. Mellström y Johannesson (2008) proporcionan una prueba experimental del efecto desplazamiento en la donación de sangre; la oferta de donantes de sangre es mayor cuando no hay pagos que cuando estos están presentes.

Así, la idea de que otros dependen de nuestra generosidad y de nuestro sentimiento de solidaridad con ellos, y de que, simultáneamente, nosotros en una emergencia podemos necesitar la asistencia de un extraño son opiniones y sentimientos incompatibles con presencia de incentivos mercantiles, sean estos reales o percibidos. La presunción de donación para incentivar la oferta de órganos es una opción con riesgos, si el altruismo se atrofia no estará disponible cuando se le necesite.

\section{Conclusiones}

Incrementar la tasa de donación cadavérica implica mejorar la capacidad de las agencias encargadas de la obtención de órganos para concretar la actitud positiva hacia el trasplante, lo que permite que las donaciones potenciales se conviertan en donaciones efectivas. Las leyes de presunción de donación tienen como característica extender al máximo la donación potencial, pero ello no implica, per se, que las tasas de donación efectiva se incrementen. Si no se trasmite de manera adecuada la información y los incentivos acerca de la donación de órganos, los individuos pueden desconfiar del modelo de donación y de sus instituciones y, en consecuencia, manifestar su negativa a donar órganos.

En particular, si los individuos perciben que el modelo de donación de órganos permite el beneficio individual de algún actor dentro del sistema, por encima de la consideración del beneficio público, se puede generar una reacción adversa a la donación de órganos, lo que eventualmente puede agravar el problema de escasez de órganos para trasplante. Esto puede ocurrir en contextos donde el sistema de salud funciona desde la lógica de incentivos de mercado, donde hay problemas como ineficiencia, falta trasparencia y sospechas de corrupción. 
Los modelos de obtención de órganos deben garantizar que los potenciales donantes reciban la información completa y clara, evitar que esta llegue de manera distorsionada al receptor. No puede descuidar la proactividad de los programas de detección de donantes y la generación de una atmósfera social positiva, lo cual pasa por generar una cultura de la donación que promueva el sentido de comunidad y de benevolencia como motivos de la donación.

La bioética tiene un campo de estudio privilegiado en el análisis de todo el proceso del trasplante de órganos, desde los dilemas éticos asociados a las diversas técnicas y modelos institucionales de obtención de órganos, hasta los problemas que enfrenta al momento de asignación de órganos disponibles entre los potenciales donantes, o los criterios de ordenación de la lista de espera. En todos los casos la bioética, con su conocimiento amplio de las posibilidades tecnológicas, su juicio en el estudio de las relaciones entre ética y derecho y su conocimiento del entorno, puede contribuir a identificar los peligros potenciales y proporcionar información útil para que la población se haga partícipe de debates vitales, pues en temas como la donación y el trasplante de órganos no solo se compromete la supervivencia y la calidad de vida de algunos individuos, sino que además se definen los valores y el tipo de sociedad que queremos.

\section{Referencias}

Abadie, A. y Gay, S. (julio, 2006). The impact of presumed consent legislation on cadaveric organ donation: A cross-contry study. Journal of Health Economics, 25(4), 599-620. DOI: https://doi.org/10.1016/j. jhealeco.2006.01.003
Barcellos, F. C., Araujo, C. L. y Da Costa, J. D. (2005). Organ donation: a population-based Study. Clinical Transplantation, 19(1), 33-37. DOI: https://doi.org/10.1111/j.1399-0012.2005.00280.x

Becker, G. S. y Elias, J. J. (2007). Introducing Incentives in the Market for Live and Cadaveric Organ Donations. Journal of Economic Perspectives, 21(3), 33-24. DOI: https://doi.org/10.1257/jep.21.3.3

Byrne, M. M., y Thompson, P. (junio de 2001). A positive analysis of financial incentives for cadaveric organ donation. Journal of Health Economics, 20(1), 69-83.

Chaparro, G. R. (enero-junio, 2016). El mercado de órganos humanos. Semestre Económico, 19(39), 113-130. DOI: https://doi. org/10.22395/seec.v19n39a5

Colombia, Congreso de Colombia (2016). "Ley No. 1805 del 4 de agosto de 2016”, Por medio de la cual se modifican la Ley 79 de 1988 y la Ley 919 de 2004 en materia de donación de componentes anatómicos y se dictan otras disposiciones. Bogotá, Colombia.

Cosse, T. J. y Weisenberger, T. M. (diciembre, 2000). Words versus actions about organ donation: A four-year tracking study of attitudes and self-reported behavior. Journal of Business Research, 50(3), 297-303.

Domínguez, J. y Rojas, J. L. (mayo, 2013). Presumed consent legislation failed to improve organ donation in Chile. Transplantation Proceedings, 45(4), 1316-1317. DOI: https://doi.org/10.1016/j.transproceed.2013.01.008

Frey, B. S. y Oberholzer-Gee, F. (septiembre, 1997). The cost of price incentives: An 
empirical analysis of motivation crowding-out. The American Economic Review, 87(4), 746-755.

Gallup Organization. (1993). The american public's attitudess toward organ donation and transplantation. Boston: The Partnership for Organ Donation.

Instituto Nacional De Salud, Coordinación Nacional Red Donación y Trasplantes (2016). Informe Anual Red De Donación y Trasplantes Colombia: Año 2015, volumen 5. Recuperado de http://www.ins.gov.co/lineas-de-accion/Red-Nacional-Laboratorios/Estadsticas/Informe\%20Red\%20 de\%20Donación\%20y\%20Trasplante\%20 2015.pdf

Kaserman, D. L. y Barnett, A. H. (junio, 1991). An Economic Analysis of Transplant Organs: A Comment and Extension. Atlantic Economic Journal, 19(2), 57-63. DOI: https://doi.org/10.1007/BF02299076

Mellström, C., y Johannesson, M. (junio, 2008). Crowding out in blood donation: Was Titmuss right? Journal of the European Economic Association, 6(4), 845-863. DOI: https://doi.org/10.1162/JEEA.2008.6.4.845

Morgan, S. E., Harrison, T. R., Long, S. D., Afifi, W. A. et al. (octubre, 2005). Family discussions about organ donation: how the media influences opinions about donation decisions. Clinical Transplantation, 19(5), 674-682. DOI: https://doi.org/10.1111/ j.1399-0012.2005.00407.x

Registro Internacional en Donación y Trasplante de Órganos [Irodat]. (15 de agosto de 2016). Database. International Registry in Organ Donation and Transplantation. Re- cuperado de http://www.irodat.org/?p=database

República de Colombia. (11 de noviembre de 2014). "Proyecto de Ley 091 de 2014" Camara. Gaceta del Congreso, (489). Bogotá, Colombia.

Reynolds, R. L. y Barney, L. D. (junio, 1988). Economics of organ procurement and allocation. Journal of Economic Issues, XXII(2), 571-579. DOI: https://doi.org/10.1080/002 13624.1988.11504787

Rithalia, A., McDaid, C., Suekarran, S., Myers, L. y Sowden, A. (enero, 2009). Impact of presumed consent for organ donation on donation rates: a systematic review. British Medical Journal, 338(7689), 1-8. DOI: https://doi.org/10.1136/bmj.a3162

Rodrigue, J. R., Cornell, D. L. y Howard, R. J. (enero de 2006). Organ donation decision: Comparison of donor and nondonor families. American Journal of Transplantation, 6(1), 190-198.

Titmuss, R. M. (1972). The Gift Relationship. From Human Blood to Social Policy. Nueva York: Vintage Books.

Universidad Diego Portales. (2011). Estudio sobre donación de órganos para trasplantes. Recuperado el 18 de agosto de 2016, de http://www.udp.cl/investigacion/repo_ detalle.asp?id=106

Zúñiga, A. (octubre , 2015). El consentimiento presunto y la reciprocidad como mecanismos para aumentar la donación. $R e$ vista Médica de Chile, 143(10), 1331-1336. DOI: https://doi.org/10.4067/S003498872015001000012 